\title{
THE APPLICATION OF IMPROVED CUCKOO SEARCH IN CASCADE RESERVOIR POWER GENERATION OPTIMIZED OPERATION
}

\author{
Wenlin YUAN ${ }^{1}$, Meiqi $\operatorname{LIU}^{1 *}$, Fang $\mathrm{WAN}^{2,3 * *}$ and Fuqiang $\mathrm{WANG}^{2,3,4}$
}

${ }^{1}$ School of Water Conservancy and Environment, Zhengzhou University, Zhengzhou 450001, China

${ }^{2}$ School of Water Conservancy, North China University of Water Resources and Electric Power, Zhengzhou 450045, China

${ }^{3}$ Collaborative Innovation Center of Water Resources Efficient Utilization and Support Engineering, Zhengzhou 450046, China

${ }^{4}$ Henan Key Laboratory of Water Environment Simulation and Treatment, Zhengzhou 450046, China

*Corresponding author email: liumq7656@163.com;**wanxf1023@163.com

(Received May 2018; accepted July 2018)

Key words: cascade reservoir, power generation optimal operation, Cuckoo search, new neighbor sequence algorithm, variable neighborhood descent algorithm

\begin{abstract}
Cuckoo algorithm based on random walk of Levy flight search mechanism leads to instability of solutions and a tendency to get trapped in local optimal solution. Based on the characteristics of the optimal operation of cascade reservoir power generation, the paper proposes an improved cuckoo algorithm that features a new neighbour sequence algorithm for global search and a variable neighbourhood descent algorithm for local search, and applies the improved cuckoo algorithm to optimizing the operation of cascade reservoir power generation. Through case study, the paper proves the reasonability and reliability of the hybrid algorithm, and that the improved cuckoo algorithm provides more efficient and stable solutions, representing a new exploration about the optimal scheduling model for high-dimensional and complex cascade reservoirs power generation and operation.
\end{abstract}

Palabras clave: embalse de cascada, operación óptima de generación de energía, búsqueda cuco, nueva secuencia del algoritmo del vecino, algoritmo descendente de vecindad variable

\section{RESUMEN}

El algoritmo cuco basado en una corrida aleatoria del mecanismo de búsqueda ligero de Levy lleva a soluciones inestables y a la tendencia de quedar atrapados en la solución óptima local. Con base en las características de operación óptima de generación de energía en un embalse de cascada, este trabajo propone un algoritmo cuco mejorado que presenta una nueva secuencia de algoritmo de vecino para búsqueda global y una secuencia variable del algoritmo de vecindad descendente para búsqueda local, que aplica el algoritmo cuco mejorado para optimizar la operación de generación de energía en el embalse de cascada. A través de un estudio de caso este trabajo prueba la razonabilidad y la confiabilidad del algoritmo híbrido y que el algoritmo cuco mejorado da soluciones más eficientes y estables, lo que representa una nueva exploración acerca del modelo óptimo de programación para la generación y operación de energía en embalses de cascada complejos y de grandes dimensiones. 


\section{INTRODUCTION}

The joint optimal operation of cascade hydropower stations in China has significant academic value and practical implications in improving water resources utilization, protecting river ecosystem, ensuring the safe and economical operation of power grids. Optimization of cascade reservoirs power generation and operation is a nonlinear, multistage and constrained combinatorial optimization problem (Zhao et al. 2005, Yang et al. 2017, Li et al. 2018, Su et al. 2016, Razali et al. 2017). The mathematical models involved are high-dimensional, complex, dynamic and nonlinear. Therefore, the core problem in optimizing cascade reservoirs operation is to establish a reasonable optimal scheduling model and adopt a suitable solution method (Chen et al. 2008, Palinkas et al. 2016, Zhang and Lee 2017, Feng et al. 2017, Ali et al. 2017).

Due to unstable convergence results and the dimension disaster problem, traditional methods such as linear (or nonlinear) programming, dynamic programming, grid flow method and large-scale system have been replaced by intelligent algorithms such as ant colony algorithm, particle swarm optimization, and genetic algorithm (Su et al. 2016, Guo et al. 2010, Zhou and Ji 2007, Zhang et al. 2013, Karami et al. 2017, Haruna and Hanafiah 2017, Franco et al. 2017, Sharma and Yadav 2017). The intelligent algorithm has the advantages of simple principle, parallel search and global optimization and easy application. It is widely used in the optimal scheduling of cascade reservoirs.

With the rapid development of computer technology, domestic and foreign experts are applying multi-point interactive search evolutionary algorithm of biological populations in for complex solution space to the optimal scheduling of cascade reservoirs. Although intelligent algorithms do not have the dimension disaster problem of traditional methods, the parameters are too many and difficult to determine, and solutions unstable. (Sun et al. 2014, Yuan et al. 2008, Jia et al. 2008, Ming et al. 2015, Khan et al. 2017). To solve the problems, the paper proposals an improved cuckoo search algorithm for the optimal scheduling of cascade reservoir.

\section{MATERIAL AND METHODOLOGY}

\section{Mathematical model for optimal scheduling of cascade reservoir}

Optimization of cascade reservoir hydropower generation and operation has reservoir capacity compensation, hydrological compensation and power compensation effects. The paper takes the maximum power generation of cascade reservoir during scheduling as the optimization criteria, with the objective function and constraints are as follows.

\section{The objective function}

$\mathrm{E}=\operatorname{Max} \sum_{t=1}^{T} \sum_{i=1}^{M} A(i) \times Q(i, t) \times H(i, t) \times \Delta t$

Where $\mathrm{E}$ is the total electric generation of cascade reservoir in scheduling periods; $t$ and $T$ are the sequence number and total number of scheduling period(s); $i$ and $M$ are the sequence number and total number of the cascade reservoir(s) respectively; $A(i)$ is the coefficient of the number $i$ hydropower station; $Q(i, t)$ and $H(i, t)$ are the average power discharge and net head of the number $i$ reservoir in number $t$ period respectively; $\Delta t$ is time step.

\section{Constraints}

water balance constraints

$\mathrm{V}(i, t+1)=V(i, t)+\left(Q_{\text {in }}(i, t)-Q_{\text {out }}(i, t)\right) \times \Delta t$

Where $\mathrm{V}(i, t)$ and $\mathrm{V}(i, t+1)$ are the initial capacity and final capacity of the number $i$ reservoir in number $t$ period respectively; $Q_{i n}(i, t)$ and $Q_{\text {out }}(i, t)$ are the average inflow and discharge of the number $i$ reservoir in number $t$ period.

Balance constraints of inflow

$Q_{\text {In }}(i+1, t)=Q_{\text {out }}(i, t)+q(i, t)$

Where $\mathrm{q}(i, t)$ is local inflow between the number $i$ reservoir and the number $i+1$ reservoir. Since it is a mid-to long-term dispatch, the time lag of water flow can be ignored.

Constraints of water level

$Z_{\text {min }}(i, t) \leq Z(i, t) \leq Z_{\max }(i, t)$

Where $Z(i, t)$ is the average water level of the number $i$ reservoir in number $t$ period; $Z_{\max }(i, t)$ and $Z_{\min }$ $(i, t)$ are the maximum level and the minimum level of the number i reservoir in number $t$ period; $Z_{\max }$ $(i, t)$ is the dead water level; $Z_{\max }(i, t)$ is determined by comprehensive requirements of flood protection, downstream consumption and so on.

Constraints of water discharges

$Q_{\min }(i, t) \leq Q(i, t) \leq Q_{\max }(i, t)$ 
Where $Q(i, t)$ is the average discharge of the number i reservoir in number $t$ period; $Q_{\max }(i, t)$ and $Q_{\min }$ $(i, t)$ are the maximum discharge and the minimum discharge of the number $i$ reservoir in number $t$ period $Q_{\min }(i, t)$ is determined by the requirements of ecological water use, shipping and so on. $Q_{\max }(i, t)$ is determined by the requirements of downstream flood protection.

Constraints of plant output

$N_{\min }(i, t) \leq N(i, t) \leq N_{\max }(i, t)$

Where $N(i, t)$ is the average output of the number $i$ reservoir in number $t$ period; $N_{\min }(i, t)$ and $N_{\max }(i, t)$ are the maximum output and the minimum output of the number $i$ reservoir in number $t$ period. They are determined by the rated output of generator, hindered capacity, expected output and so on.

Non-negativity Constraints

All of these variables are non-negative.

\section{Fundamentals of Cuckoo algorithm}

Cuckoo algorithm (Cuckoo Search, abbreviated $\mathrm{CS}$ ) is an intelligent bionic algorithm proposed by Cambridge University scholars Yang and Deb (Yang and Suash 2009, Ahmad et al. 2017). The algorithm with the characteristics of limited parameters and easy accessibility and prominent robustness has successfully solved practical problems such as function optimization and engineering optimization drawing the attention of scholars at home and abroad.

CS simulates the brood parasitism of some cuckoo species (Cuckoo Species) and conducts random search in the target space using Levy flight. The algorithm is based on the following three assumptions: (1) Each cuckoo produces only one egg and select its nest randomly; (2) The egg stored in the best nest can hatch a new generation; (3) The number of selected nests for spawning is limited. After found by the owner under the probability $p_{a} \in(0,1)$, cuckoo nest egg will be thrown out or the owner will abandon this nest and rebuild a new nest in another place. The basic process of the algorithm is:

(1) Randomly generate $L$ nest locations (corresponding to $L$ solutions) in the solution space, calculate the fitness value of each nest according to the setting fitness function, maintain the best position and carry out iteration of the rest;

(2) Assume the number $i$ nest location which has finished $\mathrm{k}$ iterations is $x_{i}^{k}=\left(x_{i, 1}, x_{i, 2}, \ldots x_{i, D}\right) ; 1 \leq$ $i \leq L, D$ is the dimension of the problem to be solved. Except the optimal one can be reserved directly to the next generation, the rest continues iteration as follows:

$\mathrm{x}(k+1)=x(k)+a \times k^{-\lambda},(1<\lambda \leq 3)$

Where $a>0$ is the time step determined by the scale of the problem to be solved; $k^{-\lambda}$ is a Random distribution function that abides by Lévy.

(3) Suppose the probability that owner finds the nest of cuckoo egg is $p_{a}$. Randomly generate positive number $r \in[0,1]$ which abides by uniform distribution. If $r>p_{a}$, then the cuckoo nest egg will be thrown away or the owner abandons this nest and rebuilds a new nest, otherwise it remains unchanged.

(4) Determine whether iteration has reached the predetermined times, otherwise, return to (2) and continue iteration until the iteration requirements are satisfied.

\section{Improved cuckoo algorithm}

Iterations of Cuckoo algorithm exploits the random walk of Levy flight to generate new nests, in the iterative formula, the first component in the right side of the equation means the random walk is merely a Markov chain related to the current location; the second component represents the probability of metastasis. Since Lévy light generates random step, it sometimes produces greater step that expands the search space but lowers search accuracy, or may even lead to fluctuating phenomena; sometimes it produces smaller step with higher search accuracy, but also a tendency for local optimal solution. Therefore, the following two aspects are crucial when generating a new nest:

(1) In order to avoid getting trapped in local optimal solution and to carry out global optimization, the majority of the new locations should be generated randomly and kept far away enough from the best available location at present;

(2) In order to speed up the local search, the new location should be generated in the vicinity of the best current position.

To solve the above problems, this paper proposes the following improvements.

\section{Coding strategy}

According to the features of the optimization model of Cascade Reservoir generation, an improved coding strategy put forward. Suppose the upper water level and the low water level of number m reservoir 
in period $t$ is respectively $Z_{\max }(m, t)$ and $Z_{\text {min }}(m, t)$. Divide the space between the upper and lower limit level into $I$ parts, and record the steps as $\operatorname{STEP}(m, t)$.

$\operatorname{STEP}(m, t)=\frac{Z_{\text {man }}(m, t)-Z_{\text {min }}(m, t)}{I}$

Represent the water level of number $m$ reservoir for period $t$ with a code number that is a non-negative integer $[0, I]$ If it is known that $I(m, t) \in[0, I]$, use the following formula for water level conversion.

$\mathrm{Z}(m, t)=Z_{\min }(m, t)+I(m, t) \times S T E P(m, t)$

According to the coding rule of reservoir water level above, assume that each reservoir in each period has I discrete parts, set the upper water level of the reservoir as decisive variables. For the solution of the optimal operation model of cascade hydropower generation in $T$ scheduling periods, the solution is denoted by vector of the $M \times T$ dimension $\{x(1,1)$ $x(1,2), \ldots, x(1, T), x(2,1), x(2,2), \ldots, x(M, T)\}$, where the vector $x(m, t)$ is a non-negative integer.

\section{Search mechanism}

Given the low search precision, tendency for local optimal solution, and solution instability resulting from random walk algorithm of Lévy flight in generating new solutions., The paper proposes to replace the Lévy flight search mechanism with a new neighborhood sequence algorithm for global search and a variable neighborhood depth search algorithm for local search, without increasing the number of algorithm parameters, to enhance the stability and accuracy of the algorithm (Hanoun et al. 2014, Ali and Iftikhar 2017, Khan et al. 2017).

The main calculation process of the new neighborhood sequence algorithm (New Neighbor Sequence Algorithm, hereafter referred to as NNSA):

(1) Randomly generate $p_{g} \in[0,1]$, and assume that the total number of iterations performed by CS algorithm is $K$, the current times of iterations is $k$;

(2) If $p_{g} \geq k / K$, randomly generate a solution vector denoted Best;

(3) If $p_{g}<k / K$, apply insertion operator to generate a new solution vector denoted $\mathrm{New}$ on the basis of the current optimal solution;

(4) Compare Best and New, if the fitness function value of New is better than Best's, then replace Best by New, otherwise apply exchange operator to generate a new solution vector denoted New on the basis of the current optimal solution.;
(5) Compare Best and New, if the fitness function value of New is better than Best's, then replace Best by New;

(6) Record solution vector Best.

As can be seen from the above calculation process, when the number of iterations is small, that is when $k / K$ is small, it will generate more random solution vectors, thus increase the scope of the search in the solution space, and improve the global optimization capability; as the number of iterations increases, the likelihood of generating a new solution vector in the neighborhood near the current solution vector is increasing, improving the local development level. The non-negative $p_{g}$ randomly generated determines whether a new neighborhood sequence will be generated randomly or in the vicinity of the current solution fields.

In the local search, this paper proposes the application of variable neighborhood depth search algorithm (Variable Neighborhood Descent, referred VND). The algorithm develops from variable neighborhood search algorithm (Variable Neighborhood Search, referred VNS) (Hansen et al. 2001). The basic idea of VNS is to systematically change the neighborhood structure set in the search process to expand search domain and obtain local optimal solution, and then systematically change neighborhood structure set again based on this local optimal to expand your search domain and find another local optimization solution. VND skips the random search of standard VNS algorithm, and replaces random search and local search in VNS with local search of neighborhood search. The main calculation process of the algorithm is:

(1) Assume the current optimal solution Best, the scale of problem is referred as $n=M \times T, G=1$;

(2) Apply insertion operator to generate a new solution vector recorded as New Best on the basis of the current optimal solution;

(3) If the fitness function value of New Best is better than Best's, then substitute Best with New Best and record $\mathrm{G}=0$, otherwise apply exchange operator to generate a new solution vector recorded as New Best on the basis of the current optimal solution;

(4) If the fitness function value of New Best is better than Best's, then substitute Best with New Best and record $G=0$;

(5) $G=G+1$, and determines whether $G$ has reached to $n \times(n-1)$. if reached, then record the optimal solution Best, otherwise repeat (2). 


\section{Insertion and exchange operators}

To improve the performance of the algorithm, this paper adopts the two operators of Insert and Exchange to search for the optimal solutions. Each individuals in a solution is given a real number following the above coding strategy for reservoir and water level. Assume that the current number of iterations is $k$; for the solution $X(k)=\left\{x^{k}(1,1), x^{k}(1,2), \cdots\right.$, $\left.x^{k}(1, T), x^{k}(2,1), x^{k}(2,2), \cdots x^{k}(M, T)\right\}$ to generate a new solution, the process is as below.

\section{(1) Insert}

For any non-negative integer $i, j \in[0, M \times T]$,when $i \neq j$, insert the number $i$ value before the number $j$ value in the solution vector remaining the rest unchanged, generate a new solution vector, for example $i=2, \mathrm{j}=5$, thus a new solution vector whose number of iteration is $k+1$ can be expressed as $X(k+1)=\left\{x^{k+1}\right.$ $(1,1), x^{k+1}(1,3), x^{k+1}(1,4), x^{k+1}(1,2), x^{k+1}(1,5), \cdots$, $\left.x^{k+1}(M, T)\right\}$. Its operation is shown in Fig.1.

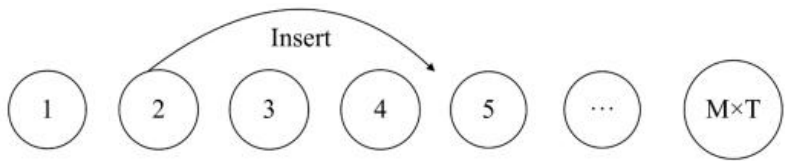

Fig. 1. A diagram of insert operation

\section{(2) Exchange}

For any non-negative integer $j \in[0, M \times T]$, when $i \neq j$, exchange the number $i$ value and the number $j$ value in the solution vector with the rest unchanged, and generate a new solution vector, for example $i=2$, $\mathrm{j}=5$. Thus a new solution vector whose number of iteration is $\mathrm{k}+1$ can be expressed as $\mathrm{X}(k+1)=\left\{x^{k+1}\right.$ $(1,1), x^{k+1}(1,5), x^{k+1}(1,3), x^{k+1}(1,4), x^{k+1}(1,2), \cdots$, $\left.x^{k+1}(M, T)\right\}$. Its operation is shown in Fig. 2.

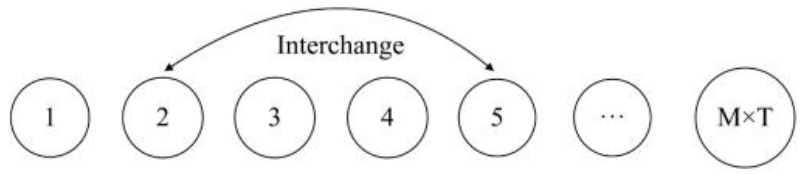

Fig. 2. The diagram of interchange operation

Based on the improvements of cuckoo algorithm above, the algorithm is a mixed cuckoo algorithm including the global search based on a new neighborhood sequence algorithm and local search based on variable neighborhood depth search algorithm, referred to as the NV-CS algorithm whose calculation process framework is shown as Fig. 3.

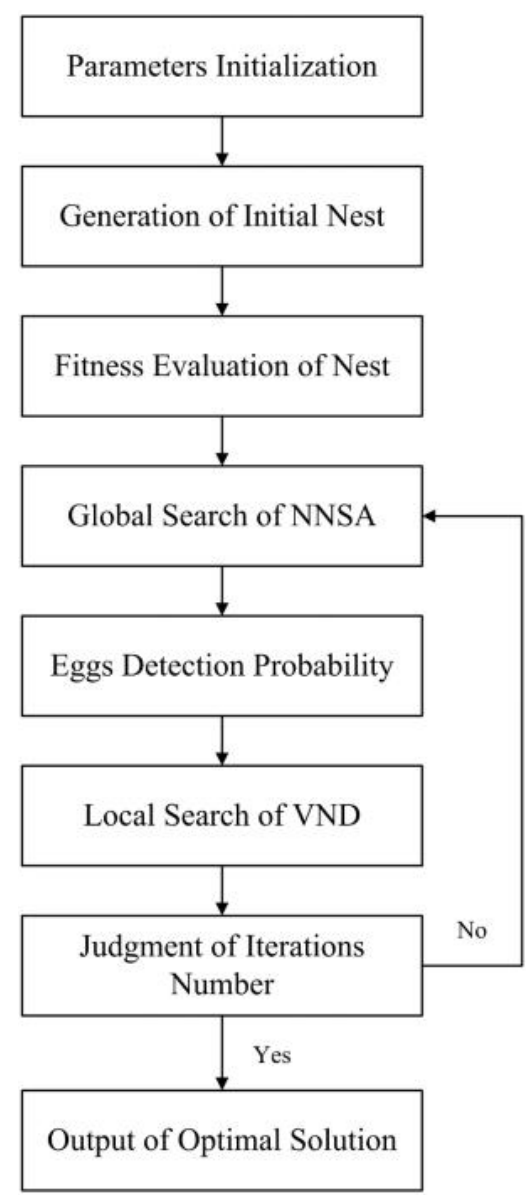

Fig. 3. The framework of improved cuckoo search

\section{Calculation process of Improved cuckoo algo- rithm using cascade hydropower generation scheduling optimization}

(1) Initialization of parameters. The basic parameters in the initialization algorithm including the number of nests $L$, detection probability $p_{a}$ and the number of iterations $K$.

(2) The generation of initial solution. According to the real number coding rules of the reservoir water level, form $L$ groups of $M \times T$ random numbers within the range of $[0, I]$ as the initial position of the nest $X(1)=\left\{X_{1}(1), X_{2}(1), \cdots, X_{L}(1)\right\}$.

(3) Quality evaluation of the nest location. adapt the fitness evaluation function shown as equation (1) to calculate the fitness of the initial position of the nest and mark best current nest position as $X_{\text {Best }}(1)$.

(4) Global search. Use NNSA algorithm to perform global search, compare the recorded optimal solution Best and $X_{\text {Best }}(1)$, and mark the better nest position of the two as $X_{\text {Best }}^{\prime}(1)$. 
(5) The probability of finding the nest. Randomly generate positive number $r \in[0,1]$ and compare it with $p_{a}$; Keep the nest less likely to be found and change the position of the nest more likely to be found. That is, keep position unchanged when $r>p_{a}$; Otherwise $I N T\left(L \times p_{a}\right)(I N T$ represents for rounding) nest locations with poor fitness will be replaced by randomly generated alternatives, to produce new nest locations $X_{1}{ }^{\prime \prime}(1)=\left\{X_{1}{ }^{\prime \prime}(1)\right.$, $\left.X_{1}{ }^{\prime}(1), \cdots, X_{L}{ }^{\prime \prime}(1)\right\}$. Calculate the fitness value of each new nest location, and mark the position of the best current nest as $X_{\text {Best }}^{\prime \prime}(1)$.

(6) Local search. Carry out elaborate local search in the best current nest position using VND algorithm, generate a new nest location $X(2)=\left\{X_{1}\right.$ (2), $\left.X_{2}(2), \cdots, X_{L}(2)\right\}$, and mark the position of the best current nest as $X_{\text {Best }}$ (2).

(7) Judgment on Algorithm termination. Repeat the above from (4) to (7), until reaching the required times of iterations, figure out the optimal solution for the current optimal solution vector by the coding strategy of reservoir levels.

\section{CASE STUDY}

\section{Basic information}

In this paper, a cascade reservoir with characteristic parameters shown in Table $\mathbf{I}$ is studied as an example. The computation time is a month. Since reservoir $\mathrm{C}$ has only a daily regulation function, only the head power is considered when calculating generation capacity. The starting and ending water levels of each reservoir during the calculation period are shown in Table II. Take the measured data of a

TABLE I. THE MAIN CHARACTERISTIC PARAMETER OF A CASCADE RESERVOIR

\begin{tabular}{lcccc}
\hline & $\mathrm{A}$ & $\mathrm{B}$ & $\mathrm{C}$ & $\mathrm{D}$ \\
\hline $\begin{array}{l}\text { Normal water } \\
\text { level(m) }\end{array}$ & 1140 & 970 & 837 & 760 \\
\hline $\begin{array}{l}\text { Dead water } \\
\text { level(m) }\end{array}$ & 1076 & 936 & 822 & 720 \\
\hline $\begin{array}{l}\text { Regulating } \\
\text { performance }\end{array}$ & $\begin{array}{c}\text { Multi-year } \\
\text { regulating }\end{array}$ & $\begin{array}{c}\text { Annual } \\
\text { regulation }\end{array}$ & $\begin{array}{c}\text { Daily } \\
\text { regulation }\end{array}$ & $\begin{array}{c}\text { Annual } \\
\text { regulation }\end{array}$ \\
\hline $\begin{array}{l}\text { Installed } \\
\text { capacity(MW) }\end{array}$ & $3 \times 200$ & $3 \times 190+125$ & $3 \times 200$ & $5 \times 250$ \\
\hline $\begin{array}{l}\text { Power output } \\
\text { factor }\end{array}$ & 8.5 & 8.35 & 8.5 & 8.17 \\
\hline
\end{tabular}

certain rainy year, as inflow runoff of Cascade Reservoir, the process of the inflow runoff and the local inflow runoff are shown in Fig.4.

TABLE II. BEGIN AND END WATER LEVEL DURING DISPATCHING PERIOD

\begin{tabular}{lcccc}
\hline Reservoir name & A & B & C & D \\
\hline Initial water level(m) & 1084 & 960 & 829.5 & 750 \\
End water level(m) & 1084 & 960 & 837 & 750 \\
\hline
\end{tabular}

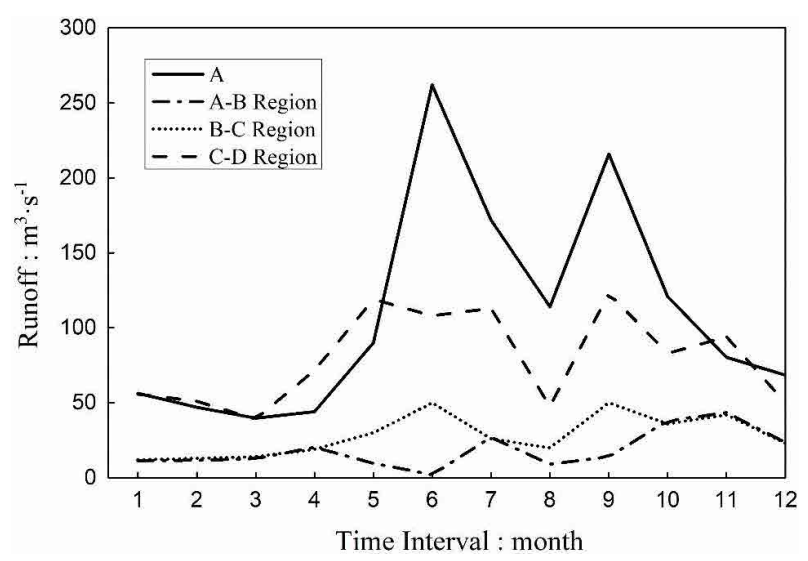

Fig. 4. The inflow hydrograph of the cascade reservoirs

\section{Case calculation}

In using the improved cuckoo algorithm for optimal scheduling solutions of Cascade hydropower generation, parameters calibration is the first step. The algorithm mainly involves three parameters: nest size $L$, detection probability $p_{a}$ and the number of iterations $K$, among which $L$ and $K$ determine the balance between accuracy and computational efficiency. Here, VB6.0 is used for encoding. When the value of $L$ and $K$ are 100, calculate probability $p_{a}$ for 10 times calculation, and use the mean value for the objective function value. The curves illustrating probability $p_{a}$ 's change with the objective function value is shown in Fig.5. When $p_{a}$ is 0.35 , the objective function value reaches the maximum value; and when the value of $p_{a}$ and $K$ are 0.35 and 100 respectively, the different values of the nest scale $L$ are calculated for 10 times. The objective function value and the calculation time are the corresponding mean value respectively. The curve illustrating $L$ 's change with the objective function value and time consumption is shown in Fig.6. When the value of $L$ is 100, the objective function value has a small change, and the 


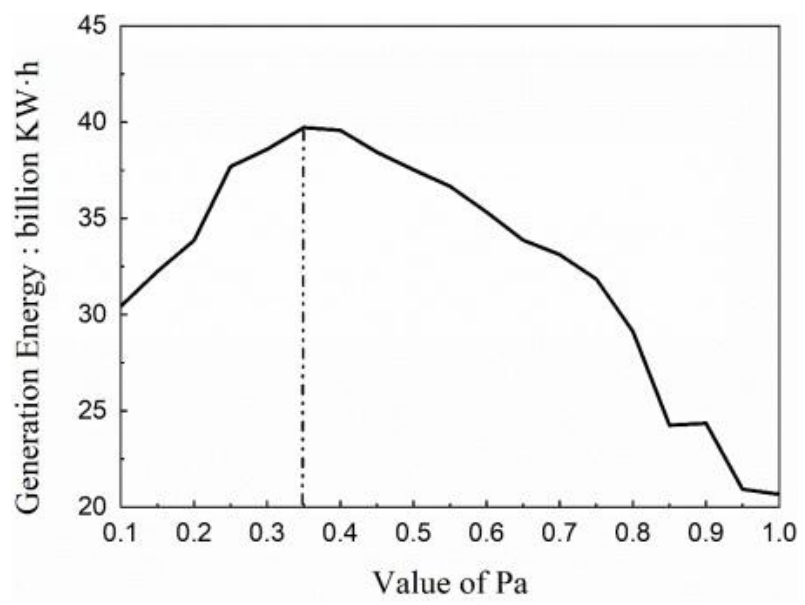

Fig. 5. The change curve of Pa value and the value of the objective function

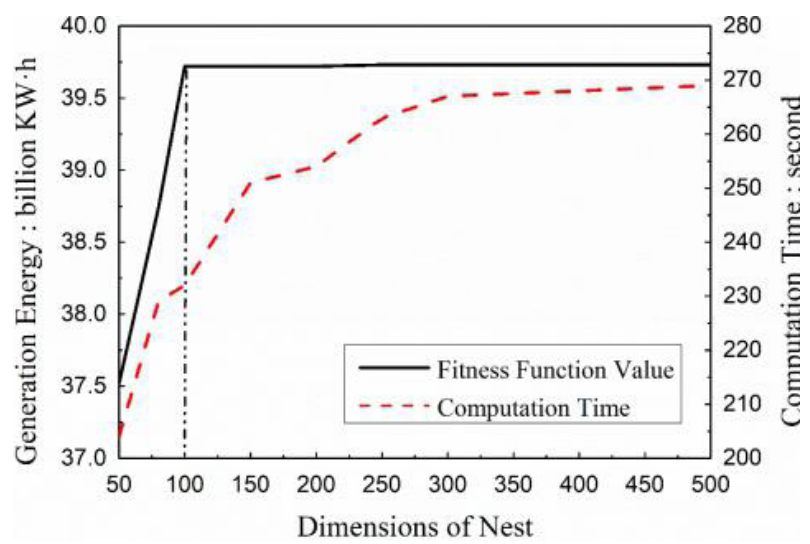

Fig. 6. The change curve of the bird's nest size and value of the objective function and computation time

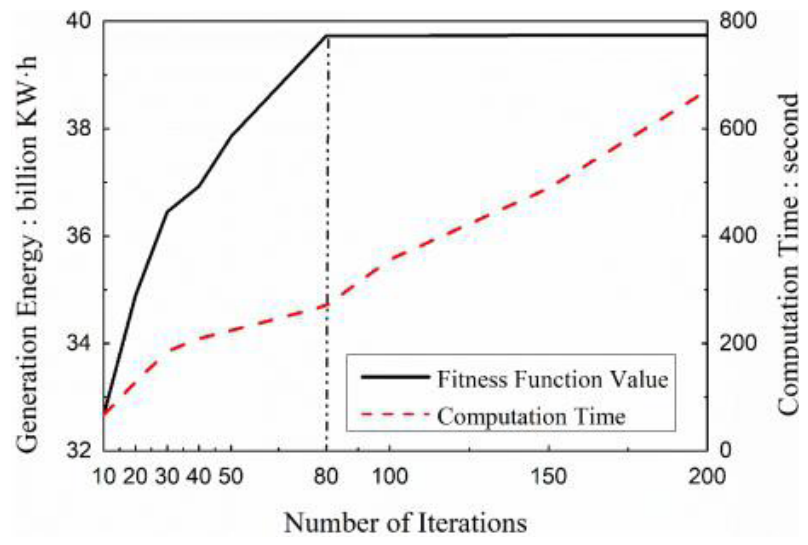

Fig. 7. The change curve of the number of iterations and value of the objective function and computation time

calculated time grows rapidly; When the value of $p_{a}$ and $K$ are 0.35 and 100 respectively, the different values of the nest scale $L$ are calculated for 10 times, and the objective function value and the calculation time are the corresponding mean value respectively. The curve illustrating $K$ 's change with the objective function value and time-consuming is shown in Fig.7. When the value of $K$ is 80 , the objective function value shows a small change, and the calculated time grows rapidly. In sum, the parameters nest size $L$, detection probability $p_{a}$ and the number of iteration $K$ are 100, 0.35 and 80 respectively. The results are shown in Table III.

The comparison of the calculation results from Improved cuckoo algorithm and basic cuckoo algorithm is as shown in Table IV. The calculation

TABLE III. THE COMPUTATION RESULT OF NV-CS

\begin{tabular}{|c|c|c|c|c|c|c|c|c|c|}
\hline & \multicolumn{3}{|c|}{ A } & \multicolumn{3}{|c|}{ B } & \multicolumn{3}{|c|}{$\mathrm{D}$} \\
\hline & $\begin{array}{c}\text { Power } \\
\text { Flow } \\
\left(\mathrm{m}^{3} / \mathrm{s}\right)\end{array}$ & $\begin{array}{c}\text { Average } \\
\text { Upstream } \\
\text { Level (m) }\end{array}$ & $\begin{array}{c}\text { Average } \\
\text { Output } \\
(\mathrm{kW})\end{array}$ & $\begin{array}{c}\text { Power } \\
\text { Flow } \\
\left(\mathrm{m}^{3} / \mathrm{s}\right)\end{array}$ & $\begin{array}{c}\text { Average } \\
\text { Upstream } \\
\text { Level (m) }\end{array}$ & $\begin{array}{c}\text { Average } \\
\text { Output } \\
(\mathrm{kW})\end{array}$ & $\begin{array}{c}\text { Power } \\
\text { Flow } \\
\left(\mathrm{m}^{3} / \mathrm{s}\right)\end{array}$ & $\begin{array}{c}\text { Average } \\
\text { Upstream } \\
\text { Level (m) }\end{array}$ & $\begin{array}{c}\text { Average } \\
\text { Output } \\
(\mathrm{kW})\end{array}$ \\
\hline Jan & 22 & 1085.3 & 20 & 0 & 962.5 & 0 & 0.00 & 751.8 & 0 \\
\hline Feb & 46 & 1086.5 & 42 & 25 & 967.4 & 20 & 100.48 & 752.9 & 62 \\
\hline Mar & 174 & 1081.3 & 158 & 186 & 969.9 & 151 & 111.44 & 755.5 & 69 \\
\hline Apr & 37 & 1076.3 & 34 & 243 & 952.9 & 193 & 314.57 & 759.0 & 195 \\
\hline May & 21 & 1079.4 & 19 & 21 & 937.2 & 17 & 140.25 & 760.0 & 87 \\
\hline Jun & 21 & 1090.4 & 20 & 22 & 938.5 & 17 & 129.70 & 759.0 & 80 \\
\hline Jul & 21 & 1102.8 & 20 & 0 & 944.0 & 0 & 112.91 & 759.0 & 70 \\
\hline Aug & 22 & 1109.3 & 20 & 0 & 952.0 & 0 & 33.66 & 759.4 & 21 \\
\hline Sep & 36 & 1115.7 & 34 & 26 & 957.0 & 21 & 144.86 & 759.9 & 90 \\
\hline Oct & 268 & 1116.7 & 251 & 306 & 959.2 & 245 & 388.80 & 760.0 & 241 \\
\hline Nov & 353 & 1106.1 & 328 & 396 & 959.2 & 317 & 490.36 & 760.0 & 304 \\
\hline Dec & 290 & 1091.4 & 266 & 380 & 959.6 & 304 & 592.29 & 755.0 & 365 \\
\hline
\end{tabular}


TABLE IV. THE COMPUTATION RESULT OF THE EXAMPLE

\begin{tabular}{|c|c|c|c|c|c|c|}
\hline & Algorithm & A & B & $\mathrm{C}$ & $\mathrm{D}$ & $\begin{array}{l}\text { Cascade } \\
\text { Sum }\end{array}$ \\
\hline \multirow{2}{*}{$\begin{array}{l}\text { Generation } \\
\text { Energy } \\
\text { (billion } \mathrm{KW} \cdot \mathrm{h} \text { ) }\end{array}$} & NV-CS & 8.88 & 9.41 & 9.85 & 11.59 & 39.73 \\
\hline & $\mathrm{CS}$ & 8.12 & 9.06 & 9.15 & 11.36 & 37.69 \\
\hline \multirow{2}{*}{$\begin{array}{l}\text { Computation } \\
\text { Time(second) }\end{array}$} & NV-CS & \multicolumn{5}{|c|}{275} \\
\hline & CS & \multicolumn{5}{|c|}{103} \\
\hline
\end{tabular}

accuracy increases by about 5\% when using the alternative improved cuckoo algorithm including the global search based on a new neighborhood sequence algorithm and local search based on variable neighborhood depth search algorithm instead of Lévy flight's random walk, but the calculation efficiency is significantly reduced mainly due to the time-consuming application of VND to local search.

\section{CONCLUSION}

Given the advantage of less parameters in cuckoo algorithm, and aiming at search efficiency problem generated by Lévy Flight in applying the algorithm to cascade hydropower generation optimization, the paper proposes to apply the new neighborhood sequence algorithm and variable neighborhood depth search algorithm to global search and local search respectively instead of Lévy Flight random walk. Through a case analysis based on parameter calibration, the results show that the improved algorithm has significantly improved cuckoo in accuracy. It not only delivers a more satisfactory approximate optimal solution, but also better stability of solutions, representing a new exploration into the optimal scheduling model for high-dimensional and complex cascade reservoirs power generation and operation.

\section{ACKNOWLEDGMENTS}

The paper is supported by the Natural Sciences Foundation of China (51779229, 51509089, 51579101), and Distinguished Young Scholar of Science and Technology Innovation (184100510014). Sincere appreciation also goes to the China Institute of Water Resources and Hydropower Research for the help of the research. The authors would like to express their gratitude to the anonymous reviewers for their constructive comments and suggestions that have helped improve this paper.

\section{REFERENCES}

Ahmad N., Hussain T., Awan A.N., Sattar A., Arslan C., Tusief M.Q. and Mariam Z. (2017). Efficient and Eco-friendly Management of biodegradable Municipal Solid Waste (MSW) using naturally aerated Windrow Composting Technique in District Lahore Pakistan. Earth Science Pakistan. 1(1), 01-04.

Ali S., Ali R. and Iftikhar A. (2017). Physico-chemical and microbiological assessment of some freshwater aquifers and associated diseases in district ghizer, gilgit-baltistan, Pakistan. Acta Scientifica Malaysia. 1(1), 08-12.

Ali S.M.M. and Zayan J.M. (2017). Drag Reduction for A Fast Back Passenger Car (Logan). Science Heritage Journal. 1(2), 17-20.

Chen L.H., Mei Y.D. and Dong Y.J. (2008). Improved genetic algorithm and its application in optimal dispatch of cascade reservoirs. Shuili Xuebao. 39 (5), 550-556.

Feng Z., Shu-Rong Y., Hui P., Hong-Ping Y. and Jian-Zhong $X$. (2017). An empirical research on the influence of Chinese rural financial reform on cultivation of new agricultural business entities. Journal of Discrete Mathematical Sciences \&amp; Cryptography. 20 (1), 389-405.

Franco H., Gavín-Quinchuela T., Alvarado-Macancela N. and Carrión-Mero P. (2017). Participative analysis of socio-ecological dynamics and interactions. A case study of the manglaralto coastal aquifer, santa elenaecuador. Malaysian Journal of Sustainable Agriculture. 1(1), 19-22.

Guo S.L., Chen J.H. and Liu P. (2010). State-of-the-art review of joint operation for multi-reservoir systems. Advances in Water Science. 21 (4), 496-503.

Hanoun S., Creighton D. and Nahavandi S. (2014). A hybrid cuckoo search and variable neighborhood descent for single and multiobjective scheduling problems. International journal of advanced manufacturing technology. 75 (9-12), 1501-1516.

Hansen P., Mladenović N. and Perez-Britos D. (2001). Variable neighborhood decomposition search. Journal of Heuristics. 7 (4), 335-350.

Haruna S.N. and Hanafiah M.M. (2017). Consumptive Use of Water by Selected Cash Crops in Malaysia. Malaysian Journal of Sustainable Agriculture. 1(2), 06-08.

Jia R.F., Chen S.L. and Liang W. (2008). Long term optimal dispatch of large scaled hydropower station groups based on chaos optimal algorithm. Shuili Xuebao. 39 (9), 1131-1135. 
Karami A., Karamshahi A. and Shahi E. (2017). Effects of forestry practices on the regeneration and biodiversity of woody plants in the northern forest ecosystems of Iran. Geology, Ecology, and Landscape, 1(4), 264-270.

Khan A., Rehman R., Rashid H. and Nasir A. (2017). Exploration of Environmental Friendly adsorbents for Treatment of Azo Dyes from Textile Wastewater and its dosage optimization. Earth Science Pakistan. $1(1), 05-07$.

Khan I.U., Sajid S., Javed A., Sajid S., Shah S.U., Khan S.N. and Ullah K. (2017). Comparative Diagnosis Of Typhoid Fever By Polymerase Chain Reaction And Widal Test In Southern Districts (Bannu, Lakki Marwat And D.I.Khan) Of Khyber Pakhtunkhwa, Pakistan. Acta Scientifica Malaysia. 1(2), 12-15.

Li Z., Han C. and Gu T. (2018). Economics of biomass gasification: A review of the current status. Energy Sources Part B Economics Planning \& Policy. 13 (2), 137-140.

Ming B., Huang Q. and Wang Y.M. (2015). Cascade reservoir operation optimization based-on improved Cuckoo Search. Shuili Xuebao. 46 (3), 341-349.

Palinkas C.M., Barth N., Koch E.W. and Shafer D.J. (2016). The influence of breakwaters on nearshore sedimentation patterns in chesapeake bay, USA. Journal of Coastal Research. 32 (4), 788-799.

Razali A., Zuraidah M.A., John B.A. and Kamaruzzaman Y. (2017). Cytotoxicity on Mcf7 Cell Lines Exposed to An Extract of The Jacalin From Jackfruit Seed. Science Heritage Journal. 1(2), 14-16.

Sharma D. and Yadav K.D. (2017). Vermicomposting of Flower Waste: Optimization of Maturity Parameter by Response Surface Methodology. Malaysian Journal of Sustainable Agriculture. 1(1), 15-18.
Su Y., Wang F.Y. and An X.L. (2016). Coupling mechanism and coupling degree measurement model of shipbuilding industry cluster. Polish Maritime Research. 23 (1), 78-85.

Sun P., Wang L.P. and Jiang Z.Q. (2014). Application of two multi-dimensional dynamic programming algorithms in optimization of cascade reservoirs operation. Shuili Xuebao. 45 (11), 1327-1335.

Yang A., Han Y., Li S., Xing H., Pan Y. and Liu W. (2017). Synthesis and comparison of photocatalytic properties for Bi2WO6 nanofibers and hierarchical microspheres. Journal of Alloys and Compounds. 695, 915-921.

Yang X.S. and Suash D. (2009). Cuckoo search via Lévy Flights. Proceedings of World Congress on Nature \& Biologically Inspired Computing. Piscataway: IEEE Publications, 210-214.

Yuan Y.H., Zhang Y.C. and Yuan Y.B. (2008). Improved self-adaptive chaotic genetic algorithm for hydrogenation scheduling. Water Resour. Plann. Manage. 134 (4), 314-319.

Zhang M.R. and Lee C.M. (2017). Economic policy of sustainable development based on is-lm-ee model. Applied Ecology and Environmental Research. 15 (3), 785-795.

Zhang X.T., Chen S.L. and Zhang F.Y. (2013). Application of Multi-Objective Particle Swarm Optimization Based on Crowding Distance to Optimal Operation of Zhanghe Reservoir. Water Resources and Power. (4), 42-45.

Zhao M.Y., Cheng C.T. and Li G. (2005). The Present State-of-the-art in the Optimum Scheduling of MultiReservoir Systems. Hydrology. 25 (6), 18-23.

Zhou N.L. and Ji C.M. (2007). Optimal Reservoir Rule Curve Based on Ant Colony Optimization. Journal of Wuhan University of Technology. 29 (5), 61-64. 